\title{
Effects of the co-inoculation with saprobe and mycorrhizal fungi on Vaccinium corymbosum growth and some soil enzymatic activities
}

\author{
C. Arriagada ${ }^{1, *}$, D. Manquel ${ }^{1}$, P. Cornejo ${ }^{2}$, J. Soto ${ }^{1}$, I. Sampedro ${ }^{3}$, J. Ocampo $^{3}$ \\ ${ }^{1}$ Laboratorio de Biorremediación, Departamento de Ciencias Forestales. Center of Amelioration and \\ Sustainability of Volcanic Soils, Scientific and Technological Bioresource Nucleus (BIOREN), Universidad \\ de La Frontera, P.O. Box 54-D, Temuco, Chile. ${ }^{2}$ Departamento de Ciencias Químicas y Recursos Naturales. \\ Center of Amelioration and Sustainability of Volcanic Soils, Scientific and Technological Bioresource Nucleus

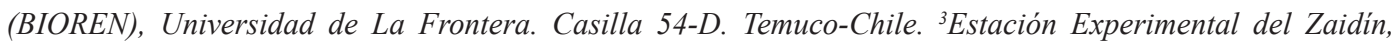 \\ Consejo Superior de Investigaciones Cientificas, Profesor Albareda 1, 18008 Granada, España. ${ }^{*}$ Corresponding \\ author: cesararriagada@ufro.cl
}

\begin{abstract}
In this study we evaluated the initial plant growth and some biochemical changes produced in rizhosphere soil of blueberry (Vaccinium corymbosum L.) cv. 'Elliot' plantlets obtained from in vitro culture and inoculated with six arbuscular mycorrhizal (AM) fungi strains (Gigaspora rosea; Glomus claroideum; G. deserticola; G. viscosum; G. intraradices and G. constrictum) and five saprobe fungi (Coriolopsis rigida; Phanerochaete chrysosporium; Trametes versicolor; Trichoderma harzianum and Penicillium chrysogenum). Our results showed a significant "like" AM root colonization (25-46\%), highlighting the treatment co-inoculated with $G$. rosea + P chrysosporium or C. rigida; G. intraradices + C. rigida; $G$. viscosum + P chrysosporium, but this root colonization was morphologically atypical, and dominated by interstitial hyphae, without develop of other typical AM structures. Furthermore, significant increase in the shoot and root growth of the plantlets inoculated with $G$. viscosum $+P$ chrysosporium, and G. intraradices $+C$. rigida were observed. On the other hand, G. claroideum $+T$. versicolor showed the high increase in the dehydrogenase enzyme activity, while inoculation with $G$. claroideum alone showed the greatest $\beta$-glucosidase activity. These results suggest that the interaction of AM symbionts together with saprobe fungi could be a biological alternative to promote the growth of micro-propagated blueberry plantlets in their early growth stages.
\end{abstract}

Keywords: Arbuscular mycorrhizae, biochemical properties, blueberries, plant symbionts, saprophytic fungi. 


\section{Introduction}

Vaccinium corymbosum L. (Ericaceae) is a shrub native from North American, which currently is extensive cropped in Chile. The surface under plantation has grown constantly since the introduction of the species into the country, reaching 12.000 ha. at present. In natural conditions this species grows in acidic soils, usually poor deficient and with high organic matter content. In this conditions, spontaneously forms mutualist symbiotic associations with certain soil fungi belonging mainly to the phylum Ascomycota, called "ericoid mycorrhizae" (Scagel et al., 2005; Smith and Read, 2008). Ericoid mycorrhizae would be specific to species of the families Ericaceae and Epacridaceae, due to their co-evolution with the native host plants growing in limiting edaphic conditions, allowing the plant to complete its life cycle (Brundrett, 2002). However, some fossil evidence indicates that originally the Ericales were able to establish arbuscular mycorrhizae (AM) (Brundrett, 2002), which have been reported in some species of this order, including several Vaccinium species (Koske et al., 1990).

Although these reports are scarce, and there is little in-depth studies in this sense (Brundrett, 2002), some authors suggest that the absence of ericoid mycorrhizal fungi inoculum may allows Ericales plants to associate with AM-forming fungi (Koske et al., 1990). Arbuscular mycorrhiza symbiosis is the most extended mutualistic association in nature, and unlike the ericoid mycorrhizae, it is not host-specific, being possible its formation between members of the phylum Glomeromycota and most of terrestrial plant species (van der Heijden, 2004; Singh, 2007).

In several micro-propagated plantlets, the application of mycorrhizal inoculants has proved to be ef- fective improving their establishment and growth at transplantation, its resistance to hydric stress, its acquisition of mineral nutrients, and increasing its tolerance to pathogens (Scagel et al., 2005; Binet et al. 2007). Furthermore, the lapse for micro-propagation during their acclimatization period can also be reduced in mycorrhizal plants (Salamanca et al., 1992).

On the other hand, the saprobe fungi are important and common components of the rhizosphere. These fungi obtain a greater nutritional benefit when living roots release organic and inorganic compounds with sloughed cells (Dix and Webster, 1995). Additionally they produce plant growth-stimulating substances such as hormones and vitamins (Shetty et al., 1994). The saprobe fungi release energy and nutrients present in complex substrates in forms which can be assimilated by the plants by means the production of extracellular enzymes, and also are capable of degrading potentially phytotoxic substances (Arriagada et al., 2009a). In addition, some of them are able to produce substances that promote the growth of other microorganisms in the rhizosphere, including AM fungi (Fracchia et al., 2000).

For these reasons, we suggest that co-inoculation with $\mathrm{AM}$ and saprobe fungi in the acclimatization stage of micro-propagated blueberry plantlets will have a beneficial influence on their growth, therefore requiring a shorter-time for their establishment in the further field conditions. Thus, the aim of the present study was to evaluate the initial susceptibility of blueberry plantlets to colonization by AM fungi, as well as the effect exercised by saprobe fungi in improving this symbiosis and promoting the growth of blueberry plantlets in the acclimatization phase. 


\section{Material and methods}

\subsection{Plant species}

After in-vitro culture (ten months) Vaccinium corymbosum cv. 'Elliot' uniform seedlings were planted in $1 \mathrm{~L}$ pots filled with a 1:4 mixture of sterilized sand and soil type Andisol, Serie Freire (pH 5.84; 10\% organic matter; $13.7 \mathrm{mg} \mathrm{kg}^{-1} \mathrm{P}-\mathrm{Olsen}$ ). The soil was sterilized at $100^{\circ} \mathrm{C}$ for $1 \mathrm{~h}$ for three consecutive days and distributed in $1000 \mathrm{~mL}$ pots. Plants were grown in a greenhouse with supplementary light provided by Sylvania incandescent and cool-white lamps (400 $\mathrm{Em}^{-2} \mathrm{~s}^{-1} ; 400-700 \mathrm{~nm}$ ) with a $16 / 8 \mathrm{~h}$ day/night cycle at $25 / 19^{\circ} \mathrm{C}$ and $50 \%$ relative humidity.

\subsection{Arbuscular Mycorrhizal fungi}

The AM fungi used in the experiment were Gigaspora rosea Nicolson and Schenck; Glomus claroideum (Schenck and Smith) Walker and Vestberg; Glomus deserticola (Trappe, Bloss and Menge); Glomus viscosum T.H. Nicolson, Glomus intraradices Schenck and Smith and Glomus constrictum Trappe, obtained from the culture collection at the Laboratorio de Biorremediación at Universidad de La Frontera, Temuco, Chile. The AM inoculum was a root-and-soil inoculum consisting of rhizosphere soil containing spores and colonized root fragments of Medicago sativa $\mathrm{L}$. in amounts of $10 \mathrm{~g}$ per pot, which were previously analyzed, showing a high potential to produce significant levels of root colonization. Plants uninoculated with AM fungi were given a filtrate (suspension of $50 \mathrm{~g}$ of fresh field soil in 11 of distilled water for 10 min and filtered through a Whatman no. 1 paper) of the soil inoculum containing the common soil microflora (principally soil bacteria), but free of AM fungal propagules.

\subsection{Saprobe fungi}

The saprobe fungi Coriolopsis rigida (Berk. Et Mont.) Murrill, Phanerochaete chrysosporium Burds, Trametes versicolor (L.:Fr.) Pillat, Trichoderma harzianum Rifai and Penicillium chrysogenum Thorn., were obtained from the fungal collection at the Laboratorio de Biorremediación at Universidad de La Frontera, Temuco, Chile. The strains were stored on Malt Extract Agar (MEA) plates at $4{ }^{\circ} \mathrm{C}$ and periodically subcultured. To prepare the fungal inoculum, barley seeds were inoculated with a $1 \mathrm{~cm}^{2}$ disk of MEA withdrawn from 14 day-old fungal cultures grown at $28{ }^{\circ} \mathrm{C}$. Ten barley seeds colonized by the mycelium of the fungi were added to the soil in each pot.

\subsection{Experimental design}

Four treatments were used: (1) Uninoculated plants (controls), (2) Soil inoculated with each saprobe fungi, (3) Soil inoculated with each AM fungi, and (4) Soil inoculated with each saprobe combined with each AM fungus. Plants were inoculated at the time of transplanting (after 4 weeks of growth). The saprobe fungi were inoculated at the same time as AM fungi. Three replicate per treatment were used.

\subsection{Harvests and analyses}

Plants were harvested after 14 weeks, dried in a airforced oven $\left(70^{\circ} \mathrm{C}, 48 \mathrm{~h}\right)$ and shoots and roots biomass were determined. After the harvest, fresh samples of roots were taken from the entire root system at random. The samples were cleared and stained using trypan blue in lactic acid (Phillips and Hayman, 1970) and the percentage of root colonized by mycorrhizal fungi was calculated by the gridline intersect method (Giovannetti and Mosse, 1980). The presence or ab- 
sence of AM colonization at each intercept was used to determine the percentage of colonization and the colonized root length.

\subsection{Biochemical determinations}

To evaluate the biochemical changes in the rhizosphere, the enzymatic $\beta$-glucosidase and dehydrogenase activities were determined. Rhizosphere soil samples were collected after harvest at direct proximity of plant roots. The $\beta$-glucosidase was determined by measuring $p$-nitrophenol (PNP) released from $p$-nitrophenyl- $\beta$-Dglucopyranoside (PNG) according to Eivazi and Tabatabai (1990). This assay is also based on the release and detection of PNP. One unit of enzyme activity was defined as $1 \mu \mathrm{mol}$ of product released per min (IU). The amount of PNP was determined in a spectrophotometer at $398 \mathrm{~nm}$. Dehydrogenase activity was determined to the method described by Trevors (1984). One gram of fresh soil was mixed with $1 \mathrm{ml}$ of buffered triphenyl tetrazolium chloride (TTC) solution and after $24 \mathrm{~h}$ incubation at $30^{\circ} \mathrm{C}$, red coloured triphenyl formazan (TPF) formed by reduction of TTC was colorimetrically determined at $546 \mathrm{~nm}$.

\subsection{Statistical analysis}

The percentage values were arcsine transformed for statistical analyses. Statistical procedures were carried out with the SPSS software, version 11.0 (SPSS Inc., 1989-2001). The data were analyzed by means of an analysis of variance (ANOVA) and the means were compared using orthogonal contrast test. Statistical significance was determined at $P<0.05$.

\section{Results and discussion}

\subsection{Root colonization}

Results showed variations in intraradical AM colonization in $V$. corymbosum roots among the different AM fungal strains used, measured principally as appressoria, intracellular hyphal coils, arbuscules as intracellular arbusculate coils like branches and intraradical hyphae (Smith and Read, 2008) (Figure 1). In all the AM fungal strains studied, morphologically the fungus seems to begin the symbiotic growth, but in no case were clearly distinguished the typical symbiotic structures (arbuscules and vesicles). Some studies as Vega et al. (2009) found high levels of AM colonization in Vaccinium plants cropped with the native populations of AM endophytes. In the present study the structures visualized in $V$. corymbosum roots resembled to dark septate endophytes (DSE), characterized by the presence of microsclerotial structures on the epidermal root cells according to described by Jumpponen (2001). In this case, the DSE colonization can reduce the AM colonization (Jumpponen and Trappe, 1998) or produce a negative effect on the extramatrical phase of the AM fungi (Scervino et al., 2009). Further studies using molecular tools are needed to corroborate the presence and extension of AM colonization in V. corymbosum roots, either in the acclimatization phase as well as in field conditions. 


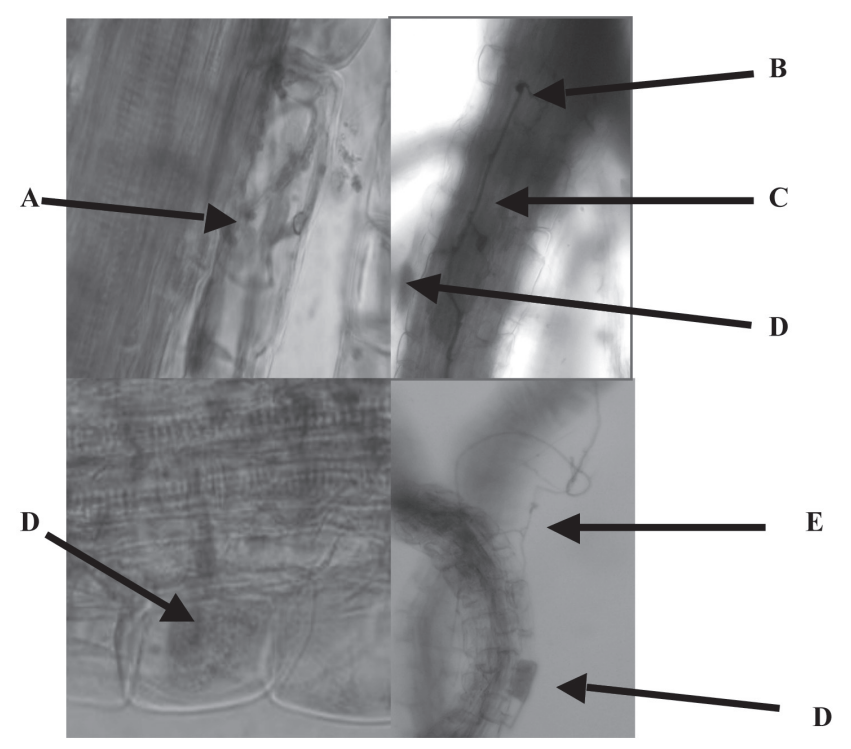

Figure 1. Arbuscular mycorrhizal fungi in cleared roots stained with trypan blue in Vaccinium corymbosum cv. ' Elliot' inoculated with G. viscosum. A: Coils in cortical cells. B: Apresoria. C: Intercellular hyphae. D: Arbuscule. E: Infective hyphae.

As Figure 2 shows, plants co-inoculated with any saprobe fungi did not showed an manifest affect on the AM colonization ( 25 and $46 \%$ for any interaction). In the Figure $2 \mathrm{~A}$ and $2 \mathrm{~F}$ the dual inoculation with $C$. rigida increases the colonization of Gigaspora rosea or $G$. intraradices (34 and 35\% respectively). The same values was observed in the Figure $2 \mathrm{~A}$ to the dual inoculation with $P$. chrysosporium and $G$. rosea $(34 \%)$; however, the dual inoculation with $P$. chrysosporium and $G$. viscosum produced a significant increase in the percentage of root coloni- zation (46\%; Figure 2D). These results suggest that $P$. chrysosporium inoculation can produce a synergistic effect on the root colonization by G. viscosum, which could be used as a biotechnological tool for improving the adaptation of Vaccinium plants at acclimatization phase. Similar effect was observed with $C$. rigida in interaction with $G$ rosea or $G$. intraradices. The specific mechanisms implicated in the beneficial effect of saprophytic fungi exudates on AM fungal colonization of roots are very complex and still poorly understood (Aranda et al., 2009). 
Figure 2. Percentage of mycorrhizal root colonization of $V$. corymbosum plants inoculated or not with the AM fungi (A: Gigaspora rosea; B: G. deserticola; C: G. claroideum; D: G. viscosum; E: G. constrictum; F: G. intraradices) and inoculated or not with the saprobe fungi (C. rigida, P. chrysosporium, T. versicolor, $T$. harzianum and $P$. chrysogenum). The data are the means \pm standard error $(\mathrm{n}=3)$.
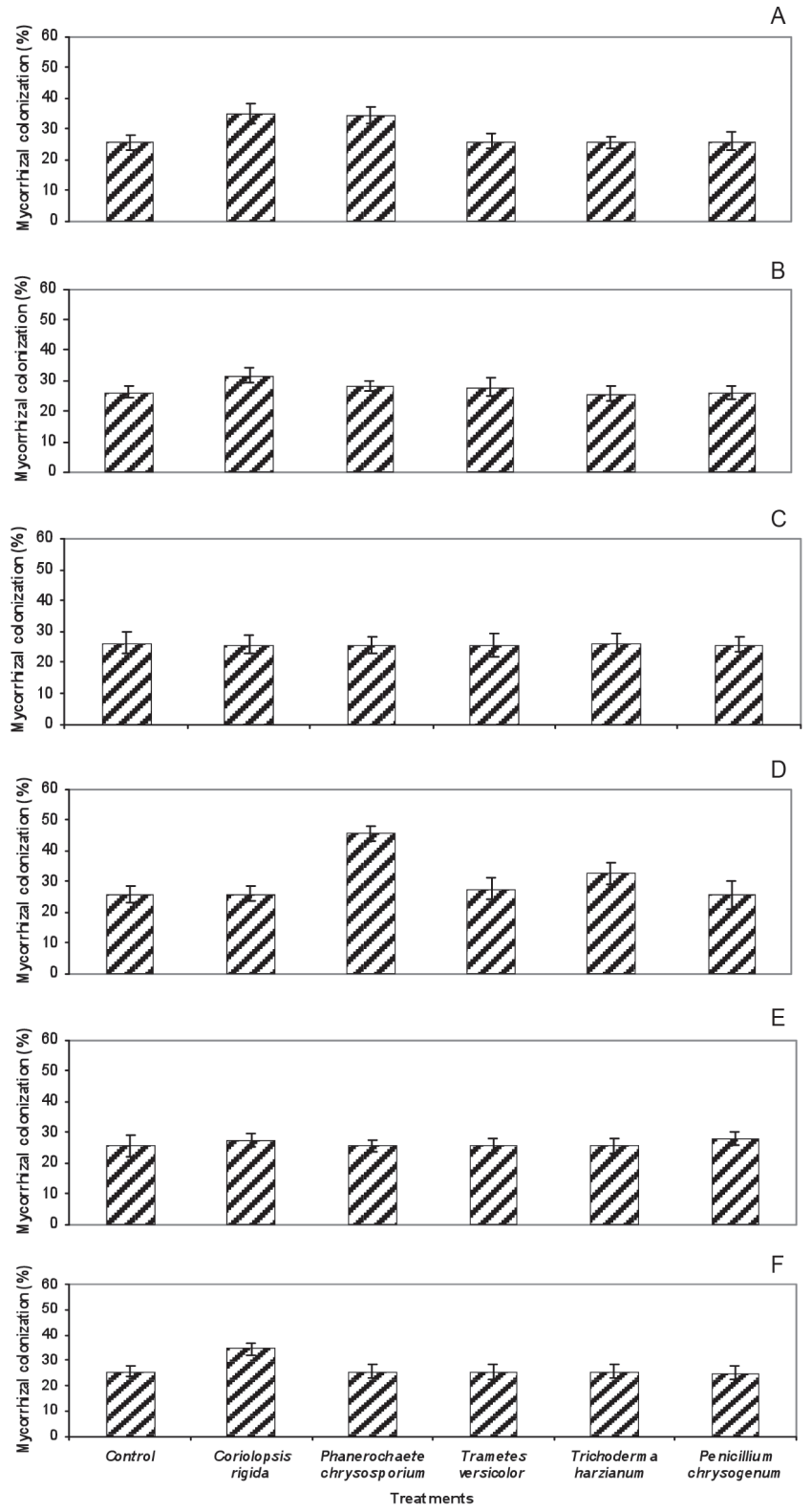


\subsection{Plant growth parameters}

Only few inoculation treatments produced a significant increase in the shoot and root biomass production compared to the control treatment (Table 1 and 2). Among the treatments including AM fungal inocu- lation, such corresponding to G. claroideum and $G$. intraradices produced the higher shoot and root biomass. Therefore, although it was not possible to demonstrate clearly the AM colonization, these results suggest that these AM fungi had a beneficial influence on plantlet growth.

Table 1. Shoot dry weight (g per plant) of $V$. corymbosum inoculated or not with the AM fungi (Gigaspora rosea, G. claroideum, G. deserticola, G. viscosum, G. intraradices and G. constrictum) or with saprobe fungi (C. rigida, P. chrysosporium, T. versicolor, T. harzianum and P. chrysogenum).

\begin{tabular}{lcccccc}
\hline \multicolumn{7}{c}{ Saprobe fungi } \\
\hline Mycorrhiza & Control & C. rigida & P. chrysosporium & T. versicolor & T. harzianum & P. chrysogenum \\
\hline Control & 0.23 & 0.29 & 0.39 & $0.86^{* *}$ & $0.65^{*}$ & $0.60^{*}$ \\
G. rosea & 0.48 & $0.73^{* *}$ & $0.73^{* *}$ & 0.43 & 0.46 & 0.45 \\
G. deserticola & 0.35 & 0.61 & 0.41 & 0.38 & 0.49 & 0.41 \\
G. viscosum & 0.41 & 0.43 & $1.33^{* * *}$ & 0.42 & $0.74^{* *}$ & 0.37 \\
G. constrictum & 0.35 & $0.67^{*}$ & 0.43 & 0.49 & 0.38 & $0.61^{*}$ \\
G. claroideum & $0.69^{*}$ & 0.22 & 0.39 & 0.41 & 0.51 & 0.33 \\
G. intraradices & 0.47 & $0.71^{* *}$ & 0.37 & 0.53 & $0.97 * *$ & 0.41 \\
\hline
\end{tabular}

Significance conventions: $* p<0.05 ; * * p<0.01 ; * * * p<0.001$

Table 2. Root dry weight (g per plant) of $V$. corymbosum inoculated or not with the AM fungi (Gigaspora rosea; G. claroideum; G. deserticola; G. viscosum; G. intraradices and G. constrictum) or with saprobe fungi (C. rigida, P. chrysosporium, T. versicolor, T. harzianum and P. chrysogenum).

\section{Saprobe fungi}

\begin{tabular}{lcccccc}
\hline Mycorrhiza & Control & C. rigida & P. chrysosporium & T. versicolor & T. harzianum & P. chrysogenum \\
\hline Control & 0.35 & 0.43 & 0.61 & 0.56 & $0.87^{*}$ & 0.53 \\
G. rosea & 0.23 & 0.35 & 0.39 & 0.29 & 0.37 & 0.34 \\
G. deserticola & 0.45 & 0.63 & 0.26 & 0.29 & 0.38 & 0.27 \\
G. viscosum & 0.45 & 0.52 & $0.99^{* *}$ & 0.45 & 0.64 & 0.36 \\
G. constrictum & 0.49 & 0.25 & 0.17 & 0.30 & 0.33 & 0.33 \\
G. claroideum & 0.47 & 0.21 & 0.28 & 0.24 & 0.37 & 0.63 \\
G. intraradices & $1.28^{* * *}$ & $1.09^{* *}$ & 0.89 & $0.76^{*}$ & 0.67 & $0.95^{* *}$ \\
\hline
\end{tabular}

Significance conventions: $* p<0.05 ; * * p<0.01 ; * * * p<0.001$ 
On the other hand, the inoculation with the saprobe fungus $T$. harzianum resulted in a significant increase of shoot and root biomass. The inoculation with saprobe fungi $P$. chrysogenum and $T$. versicolor produced the highest increase in shoot production, but this trend was not observed at root level. The improvement in the growth of plants inoculated with saprobe fungi has been reported for several plant species, and has been attributed to the production of plant growth promoting substances and antimicrobial compounds (Arriagada et al., 2009b; Arriagada et al., 2010). In addition to, several strains of the genera Penicillium fungi have been described as efficient P-dissolving fungi (Silva Filho et al., 2002).

The shoot and root biomass of plantlets co-inoculated with both mycorrhizal and saprobe fungi showed that certain particular combinations also can stimulate plant growth significantly (Table 1 and 2). This suggests a synergetic interaction between both types of fungi, resulting in a beneficial effect on plant growth (Arriagada et al., 2010). Thus inoculation with $G$. viscosum $+P$ chrysosporium, and $G$. intraradices $+C$. rigida resulted in a significant increase in the shoot and root biomass. Furthermore, the interaction between $G$. viscosum + T. harzianum; $G$. rosea $+C$. rigida; G. rosea $+P$ chrysosporium; G. intraradices + T. harzianum; G. constrictum $+P$ chrysogenum and G. constrictum $+C$. rigida resulted in a significant increase only in the shoot.

The root dry weight of $V$. corymbosum was improved by $G$. intraradices inoculated alone or together with $C$. rigida, $T$. versicolor or $P$. chrysogenum (Table 2). In this sense, some studies have shown that the transfer of carbohydrate to the AM fungi and colonized roots produce a re-distribution of photosynthates in comparison with non-mycorrhizal ones, being in this case a stronger carbon sink (Bago et al., 2000). Furthermore, the increase in root dry weight may be related with an increase in phytohormone production by the AM fungal colonization, which stimulates the development of the root system (Román García, 2003).

\subsection{Soil enzyme activity}

Certain soil enzyme activities were determined to check the effect of inoculation with AM and saprobe fungi on the biochemical and biological properties in the $V$. corymbosum rhizosphere. In general, dehydrogenase enzyme activity is considered as an index of the total microbial activity of the soil (García-Izquierdo et al., 2003; Arriagada et al., 2009a), then a greater activity would imply a higher biological oxidation of the organic matter and the concomitant higher solubilization and availability of mineral nutrients for the plants. Dehydrogenase activity in the rhizosphere of $V$. corymbosum was increased by the inoculation with all AM and saprobe fungi, but the interaction between both type of fungi not showed a remarkable difference (Table 3). In this case, among the many factors which may affect the biological activity of the soil (e.g. pH, availability of nutrients, soil humidity etc.), some studies showed that a soil $\mathrm{pH}<5$ has a negative effect on the dehydrogenase activity levels (Ramos and Zúñiga, 2008). In fact, the soil $\mathrm{pH}$ here was 5.84. This could explain the response of some combined treatments which presented a similar dehydrogenase activity to the uninoculated control. 


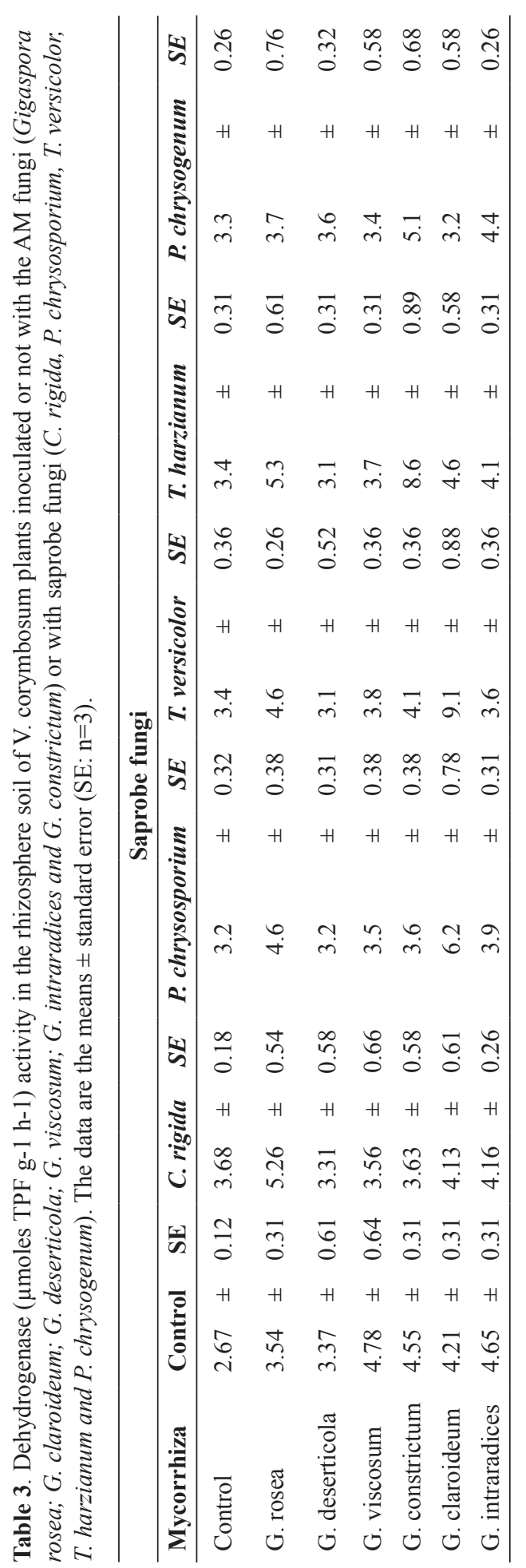

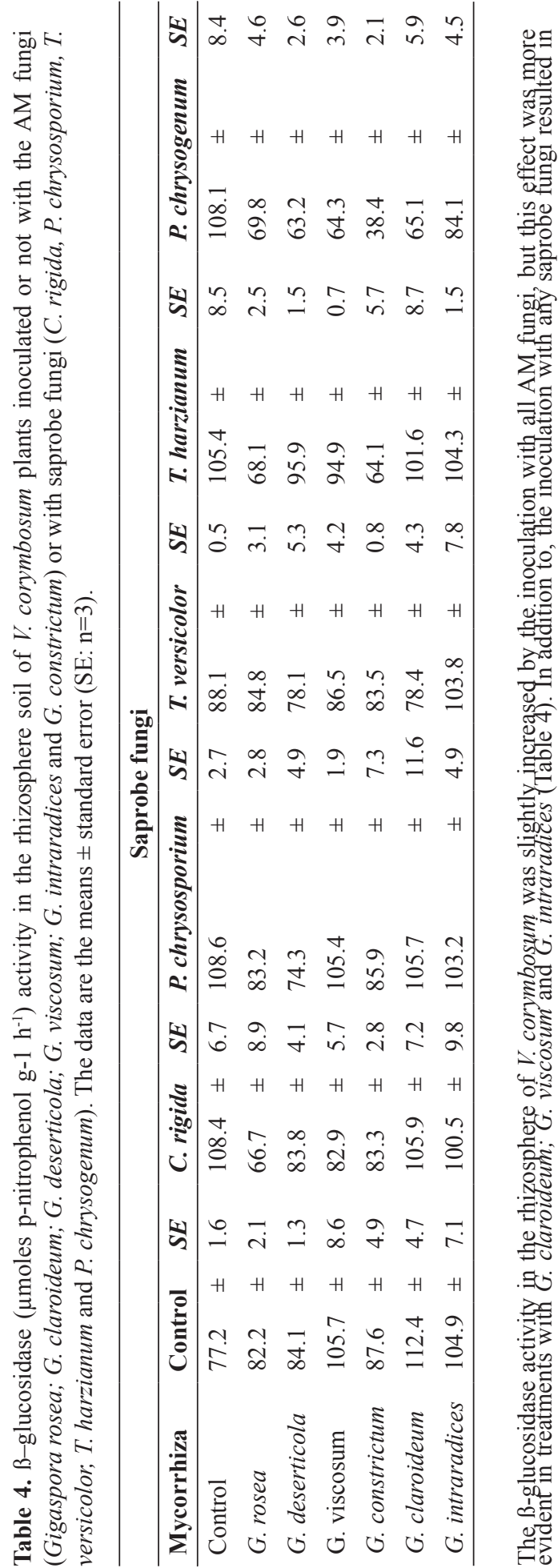


a similar increase of this activity in the rhizosphere. Therefore, although there were not significant differences evidence an increase of $\beta$-glucosidase activity, it may be suggested that the AM and saprobe fungi generate a higher demand and competition for nutrients (Arriagada et al., 2009a; Richardson et al., 2009).

\section{Conclusion}

Directed inoculation with specific AM fungi and saprobe fungi strains to the rhizosphere of $V$. corymbosum cv. 'Elliot' favored significantly the growth and development of the plantlets, thus demonstrating the beneficial effect produced by the incorporation of these plant growth promoting microorganisms during an early growth stage in the greenhouse, and allowing to reduce the acclimatization time. In this order, further studies will be focused to understand the nature of the mechanisms involved in the interactions between AM fungi, saprobe fungi and Ericaceae plants, to design strategies to improve responses in the co-inoculation with both type of fungi.

\section{Acknowledgements}

Financial support for this study was provided by the Fondo Nacional de Desarrollo Científico y Tecnológico, FONDECYT, project $\mathrm{N}^{\circ} 1100752$ and Dirección de Investigación Universidad de La Frontera.

\section{References}

Aranda, E., Sanpedro, I., Díaz, R., García-Sánchez, M., Arriagada, C.A., Ocampo, J.A., GarcíaRomera, I. 2009. The effects of the arbuscular mycorrhizal fungus Glomus deserticola on growth of tomato plants grown in the presence of olive mill residues modified by treatment with saprophytic fungi. Symbiosis. 47, 133-140.

Arriagada, C., Sampedro, I., Garcia-Romera, I., Ocampo, J.A. 2009a. Improvement of growth of Eucalyptus globulus and soil biological parameters by amendment with sewage sludge and inoculation with arbuscular mycorrhizal and saprobe fungi. Sci. Total Environ. 407, 4799-4806.

Arriagada, C., Aranda, E., Sampedro, I., GarciaRomera, I., Ocampo, J.A. 2009b. Contribution of the saprobic fungi Trametes versicolor and Trichoderma harzianum and the arbuscular mycorrhizal fungi Glomus deserticola and G. claroideum to arsenic tolerance of Eucalyptus globulus. Biores. Technol. 100, 6250-6257.

Arriagada, C., Pereira, G., Garcia-Romera, I., Ocampo, J.A. 2010. Improved zinc tolerance in Eucalyptus globulus inoculated with Glomus deserticola and Trametes versicolor or Coriolopsis rigida. Soil Biol. Biochem. 42, 118-124.

Bago, B., Pfeffer, P.E., Shachar-Hill, Y. 2000. Carbon Metabolism and Transport in Arbuscular Mycorrhizas. Plant Physiol. 124, 949-957.

Binet, M.N., Lemoine, M.C., Martin, C., Chambon, C., Gianinazzi, S. 2007. Micropropagation of olive (Olea europaea L.) and application of mycorrhiza to improve plantlet establishment. In vitro Cell Dev Biol Plant. 43, 473-478.

Brundrett, M. 2002. Coevolution of roots and mycorrhizas of land plants. New Phytol. 154, 275-304.

Dix, N.J., Webster, J. 1995. Fungal Ecology. Chapman and Hall, England, 549 p.

Eivazi, F., Tabatabai, M.A. 1990. Factors affecting glucosidase and galactosidase activities in soils. Soil Biol. Biochem. 22891-897. 
Fracchia, S., García-Romera, I., Godeas, A., Ocampo, J.A. 2000. Effect of the saprophytic fungus $F u$ sarium oxysporum on arbuscular mycorrhizal colonization and growth of plants in greenhouse and field trials. Plant Soil. 223, 175-184.

García-Izquierdo, C., Gil-Sotres, F., HernándezFernández, T., Trasar-Cepeda, C. 2003. Técnicas de Análisis Bioquímicos en suelos: Medida de Actividades Enzimáticas y Biomasa Microbiana, Mundi-Prensa Madrid, $371 \mathrm{p}$.

Giovannetti, M., Mosse, B. 1980. An evaluation of techniques for measuring vesicular-arbuscular mycorrhizal infection in roots. New Phytol. 84, 489-500.

Jumpponen, A., Trappe, J. 1998. Dark septate endophytes: a review of facultative biotrophic rootcolonizing fungi. New Phytol. 140, 295-310.

Jumpponen, A. 2001. Dark septate endophytes - are they mycorrhizal?. Mycorrhiza. 11, 207-11.

Karagiannidis, N., Bletsos, F., Stavropoulos, N. 2002. Effect of Verticillium wilt (Verticillium dahliae Kleb.) and mycorrhiza (Glomus mosseae) on root colonization growth and nutrient uptake in tomato and eggplant seedlings. Sci hortic. 94, 145-156.

Koske, R.E., Gemma, J.N., Englander, L. 1990. Vesicular-arbuscular mycorrhizae in Hawaiian Ericales. Am. J. Bot. 77, 64-68.

Phillips, J., Hayman, D.S. 1970. Improved procedures for clearing roots and staining parasitic and vesicular-arbuscular mycorrhizal fungi for rapid assessment of infection. Trans Brit. Mycol. Soc. $55,158-161$.

Ramos, E., Zúñiga, D. 2008. Efecto de la humedad temperatura y ph del suelo en la actividad microbiana a nivel de laboratorio. Ecol Apl. 7, 123-130.

Richardson, A.E., Barea, J., Mcneill, A.M., PrigentCombare, C. 2009. Acquisition of phosphorus and nitrogen in the rhizosphere and plant growth promotion by microorganisms. Plant Soil. 321, 305-339.

Román-García, F. 2003. Concentración de reguladores del desarrollo vegetal inducida por hongos endomicorrízicos en dos cultivares de Chile (Capsicum annuиm L.). Dissertation, Universidad de Colima.

Salamanca, C.P., Herrera, M.A., Barea, J. 1992. Mycorrhizal inoculation of micropropagated woody legumes used in revegetation programmes for desertified Mediterranean ecosystems. Agronomie. 12, 869-872.

Scagel, C.F., Wagner, A., Winiarski, P. 2005. Inoculation with Ericoid Mycorrhizal Fungi Alters Root Colonization and Growth in Nursery Production of Blueberry Plants from Tissue Culture and Cuttings. Small fruits review. 4, 113-135.

Scervino, J.M., Gottlieb, A., Silvani, V.A., Pérgola, M., Fernández, L., Godeas, A. 2009. Exudates of dark septate endophyte (DSE) modulate the development of the arbuscular mycorrhizal fungus (AMF) Gigaspora rosea. Soil Biol. Biochem. 41, 1753-1756.

Shetty, K.G., Hetrick, B.A., Figge, D.A., Schwab, A.P. 1994. Effects of mycorrhizae and other soil microbes on revegetation of heavy-metal contaminated mine spoil. Environ. Poll. 86, 181-188.

Silva Filho, G.N., Narloch, C., Scharf, R. 2002. Solubilização de fosfatos naturais por microrganismos isolados de cultivos de Pinus e Eucalyptus de Santa Catarina. Pesq. Agropec. Bras. 37, 847-854.

Singh, A. 2007. Molecular basis of plant-symbiotic fungi interaction: an overview. Scientific World. 5, 115-131.

Smith, S.E., Read, D.J. 2008. Mycorrhizal symbiosis. Academic Press. Third Edition. 800 p.

Trevors, J. 1984. Dehydrogenase activity in soil. A comparison between the INT and TTC assay. Soil Biol. Biochem. 16, 673-674. 
van der Heijden, M.G.A. 2004. Arbuscular mycorrhizal fungi as support systems for seedling establishment in grassland. Ecol Lett. 7, 293-303.

Vega, A.R., Garciga M., Rodríguez A., Prat L., Mella J. 2009. Blueberries mycorrhizal symbiosis outside of the boundaries of natural dispersion for ericaceous plants in Chile. Acta Hort. (ISHS) 810, 665-672. 